\title{
Antimicrobial resistance of non-clinical Escherichia coli strains from chicken in Nsukka, South-east Nigeria
}

\author{
K.F. Chah*, S.C. Okafor. and S.I. Oboegbulem \\ Department of Veterinary Patholog, Aicrobiology, Iniversity of Nigeria, Nsukka
}

\begin{abstract}
This study was carried out to determine resistance profiles of Escherichia coll strains isolated from clinically healthy chickens in Nsukka. southeas Nigeria. 1 total of $32+\mathrm{L}$. coll strains isolated from cloaca swabs from 390 chickens were tested against 16 antimicrobial agents using the disc diffusion method. The antibiotics used in the siudy were: ampicillin $(25 \mu \mathrm{s})$, amoxycillin-clavulanic acid

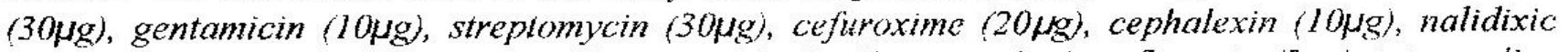
acid $(30 \mu g)$, ciprofloxacin $(5 \mu \mathrm{g})$, norfloxacin $(10 \mu \mathrm{g})$, ofloxacin $(5 \mu \mathrm{g})$, pefloxacin $(5 \mu \mathrm{g})$, tetracveline

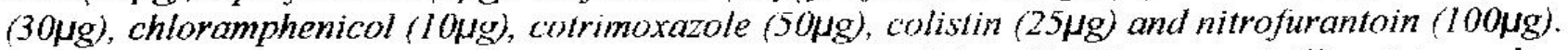

The strains demonstrated high rates of resistance $(34.6 \%$. $66.1 \%)$ to ampicillin, tetracycline, nitrofurantoin, cefuroxime and cotrimoxazole. None of the isolates was resistant to colistin, ofloxacin and pefloxacin. For each animicrobial agent (except cephalexin), strains from the intensively reared chickens (layers and broilers) displaved higher resistance frequencies than those from the local birds. A total of 49 resistant patterns were recorded for the 228 strains resistant to at least one antimicrobial drug, with $A m T e C a S$ and $A m 7 e C f N$ being the predominant patterns.

Because of the great variation in the drug resistance patterns of the Esherichia coli strains, use of antimicrobial agents in the management of $\mathrm{E}$. coli infections in the study area should be based on results of sensitivity tests.
\end{abstract}

Key Words: Antinicrobial, resistance, patterns, Escherichia coli, chicken.

\section{Introduction}

Antimicrobial resistance had been recognized since the advent of antimicrobial agents. However, the consequences of the emergence were dramatically controlled by the continued availability of offective alternatives (Neu, 1992). Unfortunately, at the moment, dnig resistance poses a scrious threat to antibiotic therapy due to the growing number of pathogens resistant to multiple, stmcturally unrclated drugs and the slow pace in developing new antimicrobials (Neu, 1992). White et al., (1997) pointed out that the emergence of resistant bacteria has been and continues to be of concern to clinicians. public health officials and clinical microbiologists.
Van den Bogaard (1993) suggested that one of the measures that must be taken to prevent emergence/spread of antimicrobial resistance was a systcmatic registration and analysis of patterns of bacteria resistance in pathogenic and non-pathogenic faccal flora. Lens (1993) also indicated that in vitro surveillance of drug resistance should be part of a package of information required on a routinc basis if the best possible use of antibiotics and a reduction of induction of resistance are to be achieved. The scriousness of the problems posed by the crolution and dissemination of multi-drug resistant bacteria is reflected by the existence of many international and national network programmes involved in the surveillance of antimicrobial resistancc in bacteria. For

\footnotetext{
*Corresponding author, e-mail: epseelon@aol.com 101
} 
Cxample. the Reservoir of Antibiotic Resistance (ROAR), an international network programme established by the Alliance for the Prudent Use of Antibiolic (APUA) is concerned with the generation of information on commensal bacteria that serve as rescrvoirs of transferable drug resistance genes. Also, in many European countries. national antimicrobial monitoring programmes (such as DANMAP and FIRE Works in Dcmmark \& Finland respectively) have been set up by the respective governments to monitor antimicrobial resistance in pathogenic and non-pathogenic human and animal bactorial species.

In much of the developing world antimicrobial susceptibility profiles of bacterial isolates are unknown (Okeke et al. 1999). In southeast Nigeria, drug resistant coliscpticaemic $I s$. coli strains were found to constitute a serious threat to poultry production (Chah and Oboegbulem. 1998: Chah et al., 2000). In the region treatment of suspected bacterial infections is based largely on "experience". Lack of velerinary diagnostic laboratories and unwillingness by the farmers to pay for cost of laboratory diagnosis were identified as the major reasons impoding isolation: idcntification and sensitivity testing of bacterial agents from animal sources prior to antimicrobial therapy (Chah and Nwcze, 2001). John and Fishman (1997) pointed out that routine susceptibility testing of bacierial isolates and surveillance of antibiotic resistance, which provides information on resistance trends including cmerging antibiotic resistance are essential for clinical practice. Thus, as part of the global efforts to currail the evolution and dissemination of drug resistant bacterial species, this study was initiated to determine resistance profiles of non-clinical $E$. coli strains from chickens in Nsukka, southeast Nigeria. The results will provide baseline information on antimicrobial resistance among $E$. coli isolates in the study area and will also act as a guide for empirical antimicrobial therapy in cases or avian $E$. coli infections.

\section{Materials and methods}

Cloaca swabs from clinically heallhy exotic chickens in poultry flocks (flock size ranged from 300 to 2000 birds) and clinically healthy local (native) chickens reared in some houscholds in Nsukka, southeast Nigeria were used in this study. The swab samples collected from a total of 390 ( 180 laycrs, 150 ) broilers and 60 local) chickens were cultured nol later than 2 hrs after collection.

Each swab was strcaked on MacConkey agar plate and incubated at $37^{\circ} \mathrm{C}$ overnight. From each plate, a single rose-pink colony was selected and streaked on cosin-methylene bluc (EMB) agar and incubated overnighi at $37^{\prime 1} \mathrm{C}$. Greenish-metallic sheen colonies on EMB were further subjocted to biochemical tests (Indole, Methyl Red, Voges-Proskauer and Simmons citrate) for $E$. coli identification as described by Edwards and Ewing (1972). Identificd $E$. coli isolates were screened for antimicrobial resistance profile using the disc diffusion method (Bauer $e t$ al., 1966). Each $b$. coli isolate was grown in rutrient broth at $37^{\circ} \mathrm{C}$ for 4 hours. Aboul $0.1 \mathrm{ml}$ of the $4 \mathrm{hr}$ broth cultures was spread on Mueller-Hinton agar. The inoculated plate was allowed 10 dry for 30 minutes before the antimicrobial discs ( 8 discs per plate) were applied on its surface. The plates were allowed on the bench for 30 minutes before they were inverted and incubated at $37^{\circ} \mathrm{C}$ for $16-18$ hours. The diameter of the zones of inhibition werc measured with a metre nulc and rocorded to the nearest whole millimetre. The zones were interpretod as resistant or sensitive following the interpretative chart of the Kirby-Bauer Sensitivity Test method (Cheesbrough, 2000). Commercial antimicrobial discs used in the study included: ampicillin (25g), amoxycillin-

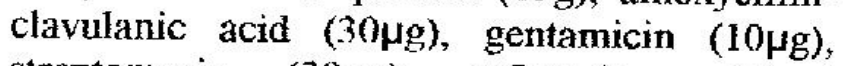
streptomycin $(30 \mu \mathrm{g})$ cefuroxime $(20 \mu \mathrm{g})$

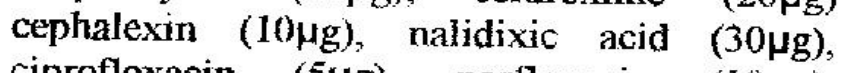

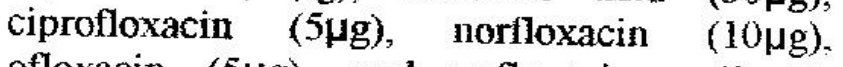

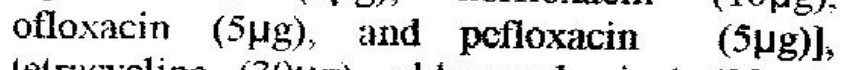

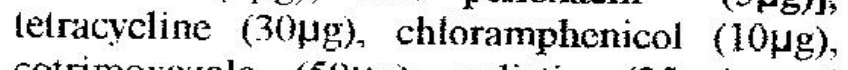

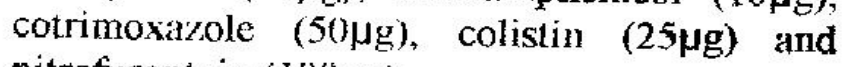
nitrofurantoin ( $10(0) \mathrm{Ng}$ ).

\section{Results}

A total of 324 Escherichia coli strains were isolated from the $\$ 90$ chickens sampled. The 
irequency of resistance of the bacterial strains to the 16 antimicrobials is presented in Table 1 .

Table 1 Frequency of antimicrobial resistance of non-clinical avian E. coli strains

\begin{tabular}{|c|c|c|c|c|}
\hline \multirow[b]{2}{*}{ fatibiotic } & \multicolumn{4}{|c|}{ No. $(\%)$ of resistant strains } \\
\hline & $\begin{array}{l}\text { Lavers } \\
(n-162)\end{array}$ & $\begin{array}{l}\text { Broilers } \\
(\mathrm{n}=112)\end{array}$ & $\begin{array}{l}\text { Local chickens } \\
(n=50)\end{array}$ & $\begin{array}{l}\text { Total } \\
(\mathrm{n}=324)\end{array}$ \\
\hline 1-apicillin (25ug) & $112(69.1)$ & $88(78.6)$ & $14(28)$ & $214(6,6,1)$ \\
\hline ztracycline $(30 \mu \mathrm{g})$ & $81(50.0)$ & $90(80.4)$ & $4(8)$ & $175(54.0)$ \\
\hline 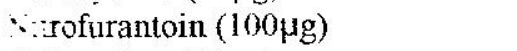 & $73(45.1)$ & $61(54.5)$ & $5(10)$ & $139(42.9)$ \\
\hline - furoxime $(20 \mu \mathrm{g})$ & $58(35.8)$ & $48(42.9)$ & $0(0)$ & $125(38.6)$ \\
\hline strimoxazole $(50 \mu \mathrm{g})$ & $54(33.3)$ & $58(51.8)$ & $0(0)$ & $112(34.6)$ \\
\hline 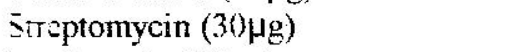 & $12(7,4)$ & $78(69.6)$ & $4(8)$ & $94(29.0)$ \\
\hline 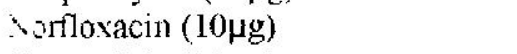 & $13(8.0)$ & $31(27.7)$ & $4(8)$ & $48(14.8)$ \\
\hline 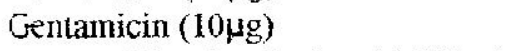 & $28(17.3)$ & $12(10.7)$ & $0(0)$ & $40(12.4)$ \\
\hline Imoxycillin-clavulanic acid $(30 \mu \mathrm{g})$ & $26(16)$ & $9(8,0)$ & $4(8)$ & $39(12.0)$ \\
\hline Chloramphenicol (10 $\mu \mathrm{g})$ & $22(13.6)$ & $8(7.1)$ & $2(4)$ & $32(9.9)$ \\
\hline 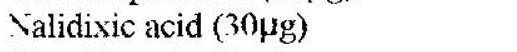 & $14(8.6)$ & $16(14.3)$ & $2(4)$ & $32(9.9)$ \\
\hline 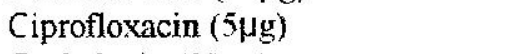 & $4(2.5)$ & $3(2.7)$ & $\mathrm{I}(2)$ & $8(2.5)$ \\
\hline Cephalexin $(10 \mu g)$ & $0(0)$ & $0(0)$ & $6(12)$ & $6(1.9)$ \\
\hline Colistin (25ug) & $0(0)$ & $0(0)$ & $0(0)$ & $0(0)$ \\
\hline 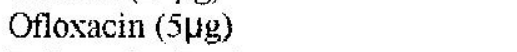 & $0(0)$ & $0(0)$ & $0(0)$ & $0(0)$ \\
\hline Pefloxacin ( $5 \mu \mathrm{g})$ & $0(0)$ & $0(0)$ & $0(0)$ & $0(0)$ \\
\hline
\end{tabular}

The strains displayed high rates of resistance $(34.6 \%-66.1 \%)$ to ampicillin, tetracycline, nitrofurantoin, ceturoxime and cotrimoxazole. Resistance rates to streptomycin, gentamicin, norfloxacin and amoxycillin-clavulanic acid were moderate $(12 \%-29 \%)$ while low rates $(1.9 \%=9.9 \%)$ were recorded for chloramphenicol, cephalexin, nalidixic acid and ciprofloxacin. None of the isolates was resistant to colistin, ofloxacin and pefloxacin. Isolates from broilers demonstrated higher rates of

Table 2 Number of antimicrobial agents to which E. colt strains were resistant

\begin{tabular}{ccccc}
\hline $\begin{array}{c}\text { No. of drugs } \\
\text { resistant to }\end{array}$ & Broilers & \multicolumn{2}{c}{ No. (\% of strains resistant) } \\
0 & $10\left(10.4^{*}\right)$ & Layers & Local chickens & Tolal \\
1 & $0(0.0)$ & $54(56.3)$ & $32(33.3)$ & $96\left(29.6^{* *}\right)$ \\
2 & $8(28.6)$ & $28(73.7)$ & $10(26.3)$ & $38(11.7)$ \\
$>2$ & $94(58.0)$ & $18(64.3)$ & $2(7.1)$ & $28(8.6)$ \\
\hline \hline
\end{tabular}

$*=\%$ of row total

$* *=\%$ of total number of E. coli strains isolated (324)

Of the 28 strains resistant to two antibiotics only two were from the local (native) chickens while 8 and 18 were from the broilers and layers respectively. Also, of the 162 strains resistant 10 more than two antibiotics 6,62 and 94 were resistance to each of the antibiotic than thosc acid, chloramphenicol and gentamicin where the reverse was the case. Of the $324 E$. coli isolates tested, $96(29.6 \%)$ were not resistant to any of the drugs while $38(11.7 \%), 28(8.6 \%)$ and 162 $(50 \%)$ strains were resistant to one, two and more than two antimicrobials respectively (Table 2). from layers, except for amoxycillin-clavulanic isolated from the local birds, lavers and broilers respectively. A total of 49 resistant patterns were recorded for the 228 strains resistant to at least one antibiotic drug. with AmTeCoS and 


\section{Chah, Okafor and Oboegbulem}

AmTeCfN being the predominant patterns (Table 3 ).

Table 3 Antimicrobial resistance patterns of non-clinical E colistrains

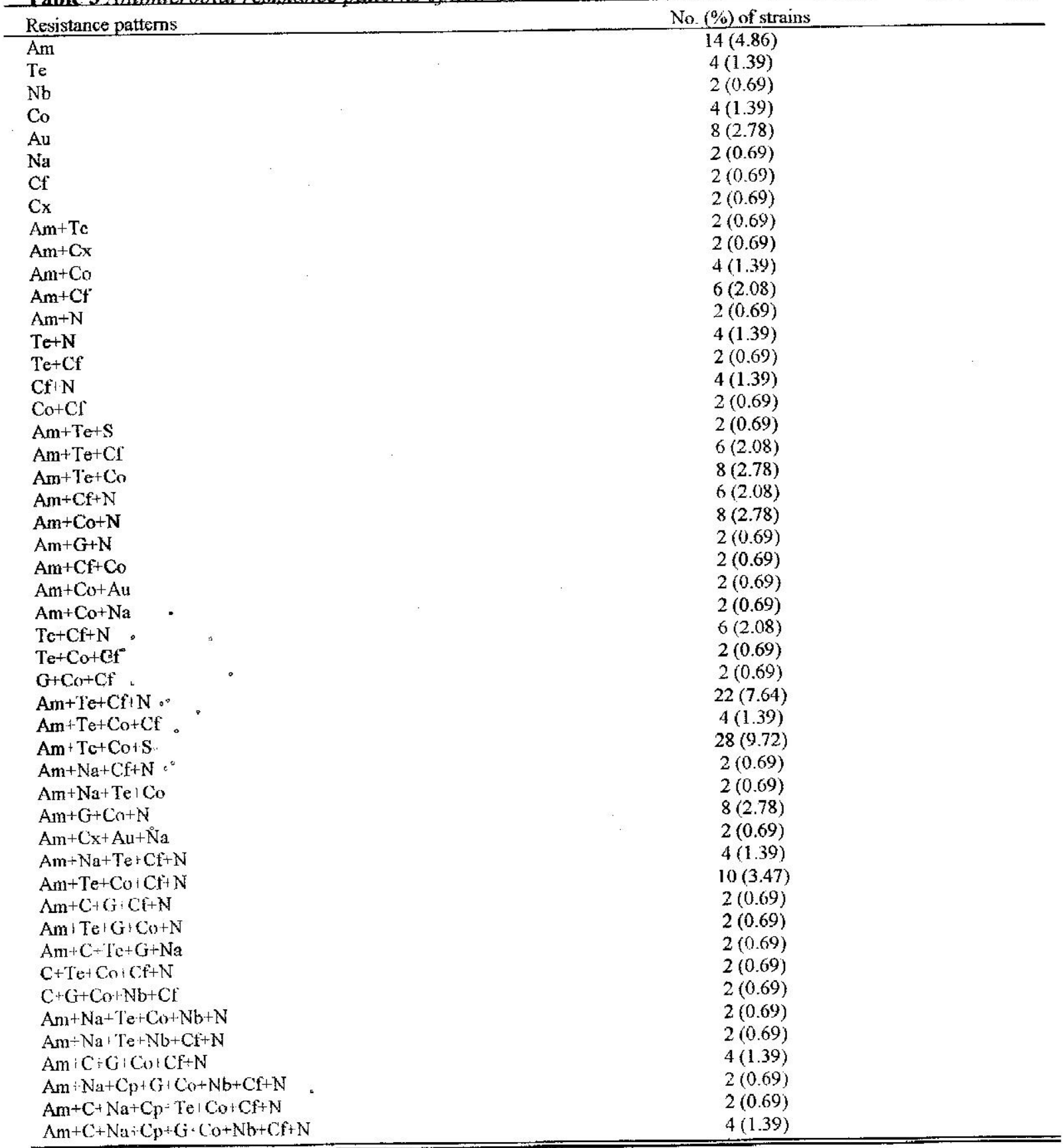

Am - Ampicillin, An - Anoxycillin-clavulanic, $\mathrm{G}=$ Gentamicin, $\mathrm{S}=$ Streptomycin,

Cf Cefurnxime, $\mathrm{Cx}-$ Cephalcxin, $\mathrm{Na}-$ Nalidixic acid, $\mathrm{CP}_{\mathrm{P}}-$ Ciprofloxacin,

$\mathrm{Nb}-$ Nortloxacin $\mathrm{Te}-\mathrm{Tetracyclinc}, \mathrm{C}=$ Chloramphenicol, $\mathrm{Co}=$ Cotrimoxazolc,

$\checkmark=$ Nitrofurantoin 


\section{Resistance profiles of non-clinical avian Escherichia coli strains}

\section{Discussion}

The non-clinical avian $E$, coli strains in this study demonstrated high rates of resistance against ampicillin, tetracycline and nitrofurantoin. However, these resistance rates are lower than those previously reported (Chah and Oboegbulem, 1998; Chah et al, 2000). This disparity may be attributed to the fact that in our previous reports clinical $E$. coli strains were used unlike in the present study. Drug preparations containing ampicillin, tetracycline or nitrofurantoin are widely used for prophylaxis, growth promotion and treatment of bacterial infections in chickens in southeast Nigeria (Chah and Nweze, 2001). Reports have shown that oral administration of antibiotics at subtherapeutic levels leads to an increase in the incidence of resistant bacteria in the intestines of animals exposed to these drugs (Levy, 1991, Helmuth and Prol:, 1997; WHO Report, 1997; Witte, 1998; Witte et al., 1999). Thus, the high resistance rates reported in this study as well as those of other previous works (Chah and Oboegbulem, 1998; Chah et al., 2000) in the area may be attributed to irrational use of antimicrobial agents in poultry production This view is also supported by the fact that isolates from local chickens (wherc antimicrobials arc rarely used) demonstrated low rates of resistance to the antimicrobial agents tested. The large number of resistance patterns recorded in this study suggest that several selcctive pressures may be involved in the induction of drug resistance among the $E$, col $i$ strains.

Presence in poultry flocks of non-clinical $E$. coli strain with high rates of resistancc to commonly available antimicrobial agents in the area poses a serious threat to the veterinarians, farmers and farm workers because they represent a 'gene pool' from which drug resistant infections might arise. Conjugal transfer of drug resistance determinants in bacteria has been reported to occur over species and genus borders (Teuber $e t$ al. 1996). Transfer of drug resistance factors to avian pathogens such as Salmonella spp and septicaemic $E$. coli strains will render arian infections causcd by these pathogens difficult to treat with the commonly available antimicrobial agents. The non-pathogenic resistant $E$. coli may colonize the human intestines where it transfers its resistance factor ( $\mathrm{R}$ - factor) to the human pathogen or other indigenous flora.

\section{Conclusion}

The results of this study and those of several previous reports (Amara et al., 1995; Blanco et al., 1997; Chah and Oboegbulem, 1998; and Chat et al., 2000) indicate an increasing incidence of multiple antibiotic resistance arnong both pathogenic and non-pathogenic $F_{\text {. }}$ coli strains. This has largely been attributed to indiscriminate use of antimicrobial agents in animal production (Blanco et al., 1997; Helmuth and Protz, 1997; WHO Repont, 1997; Witte et al., 1999). Since a large proportion of the isolates were resistant to ampicillin and tetracycline, it is recommended that the use of such drugs should only be based on results of sensitivity tests. For the treatment of avian $E$. coli infections in southeast Nigeria, the usc of drug preparations containing colistin or the fluoroquinolones such as pefloxacin, ofloxacin and ciprofloxacin is suggested. However, as pointed out by Blanco et al. (1997), the indiscriminate usc of these fluoroquinolones in animals should be avoided as this may lead to cross-resistance with other human enteric pathogens such as Salmonella and Campytohacter spp. To check the evolution and dissemination of antimicrobial resistant bacteria in the environment, there is an urgent need to establish nationally coordintaled antibiotic resistance monitoring programmes in the country. The fundamental objectives of such programmes will be to evaluate and report on a regular basis, trends on antibiotic resistance in animal and human bacteria and factors influencing the observed trends. Such reports should be made available to prescribers and users of antimicrobials and also used to cducate the general public on the dangers of irrational use of drugs in humans and animals. 


\section{Chah, Okafor and Oboegbulem}

\section{References}

Amara, A., Ziani, Z. and Bowzoubsa, $K$. 1995. Antibioresistance of Escherichia coli strains isolated in Morocco from chickens with colibacillosis. Vet. Microbiol. 43: 325 -330 .

Blanco, J. E., Blanco, M., Mora, A. aud Blanco, J. 1997. Prevalence of bacteria resistance to quinolones and other antimicrobials among avian Escherichia coli strains isolated from septicemic and healthy chickens in Spain. Joum. of Clin. Microbiol. $35: 2184-2185$.

Bauer, A.W., Kirby, W.M.W., Sherris, J.C. and Turck, M. 1966. Antibiotics susceptibility testing by standard single disk method. Am. Joum. Clin. Path. 45: $493-496$.

Chah, K. F. and Oboegbulem, S. I. 1998. Escherichia coli 053:K Extra-intestinal Outbreaks in laying flocks in Nsukka, South-east Nigeria. Bull. Anim. Hlth. Prod. Afr. $46: 263-264$.

Chah, K. F, Bessong, W. O. and Oboegbulem, S. I. 2000. Antibiotic resistance in avian colisepticamic E. coli strains in Southeast Nigeria. Proc. Nig. Soc. Anim. Prod. 25: $303-306$.

Chah K. F. and Nweze, N. E. 2001. Antibiotic use in poultry production in Nsukka, Southeast Nigeria. Proc. Nig. Soc. Anim. Prod. 26: $69-72$

Cheesbrough, M. 2000. Microbiological Tests. In: District Laboratory Practice in Tropical Countries Part 2, Low Price Edition, Cambridge University Press.

Edwards, P. R. and Ewing, W. H. 1972. Identification of Entcrobacteriaceae. $3^{\text {rit }}$ Edition; Burgess Publishing Company, Minneapolis, Minnesota.

Helmuth, R. and Protz, D. 1996. How to modify conditions limiting resistance in bacteria in animals and other reservoirs. Clin. Infect. And Dis. 24: (Suppl): S 136139.
John, J. and Fishman, N. 1997. Progranatic role of the infectious diseases physicis: is in controlling antimiciobial costs in the hospital. Clin. Infect. Dis. 24: $471-485$.

Lens S. 1993. The role of the pharmaceutical animal health industry in post-marketing surveillance of resistance. Vet. Microh. 35 : $339-347$.

Levy, S. B. 1991. Antibiotic availability and use: consequences to man and his environmcnt. $J$. Clin. Iipidemiol. $4+$ (Supl 2): $83 \mathrm{~S}-87 \mathrm{~S}$,

New, H. C. 1992. The crisis in antibiotic resistance. Science 257: $1064-1073$.

Okeke, L. N., Lamikanra, A, and Edelman, R. 1999. Sociocconomic and behavioral factors leading to acquired bactcrial resistance to antibiotics in developing countrics. Emerg. Infect. Dis. 5: $18-27$.

Teuber, M., Perreten, V., and Wirsching, F. 1996. Antibiotikumresistente bakterien: eine neue dimension in der lebensmittelmikrobiologie. Lehensmittle-technologie 29: $182-199$

Van Den Bogaard A. E. J. M. 1993. A veterinary antibiotic policy: a personal view on the perspectives in the Netherlands. Vet. Microb. 35: 303-309.

Witte, W. 1998. Medical consequences of antibiotic usc in ugriculture. Science, 279: 996-997.

Witte, W., Klare, L and Werner G.1999. The use of antibiotics as growth promoters in animal husbandry and antibiotic resistance in bacterial pathogens of human. Fleischwirtschaft. Vol. 79, ISS. 4 PP $90-94$

White, D. G., Maneewannakul, K, Von Hofe, E., Zillman, M., EisenbI R. G., Field, A. Kr and Levy, B. 1997. Thibition of the multiple antibiotic resistance (mar) operon in Fscherichio coli by antisense DNA analogs. Antmicrobial Agents Chemotherapy. 41: 2699. 2701

WHO Report. 1997. The medical impact on the use of antimicrobials in food anmals. WHO/EMC/ZOO/97.4.

(Received 09 August 2001:-1ccepted 13 September 2002) 